\title{
Bom tấn chuyển nhượng: F1000 Research gia nhập hệ thống xuất bản Taylor \& Francis
}

\author{
Nguyễn Thị Linh \\ SSHPA Data Team \\ Hà Nội, 18-01-2020
}

\begin{abstract}
Ngay đầu năm 2020 vừa qua, nhà xuất bản Taylor \& Francis đã chính thức công bố bản hợp đồng bom tấn mới: F1000 Research [1].

Ra mắt vào năm 2013, F1000 Research là nền tảng xuất bản mở đầu tiên trên thế giới [2], tiên phong trong thực hiện các ý tưởng về xuất bản mở, phản biện mở, dữ liệu mở. Các nghiên cứu trên F1000 Research sẽ luôn được công bố sớm trong khoảng 14 ngày kể từ khi nộp. Sau đó, các tác giả sẽ nhận được lời phê bình và gợi ý từ các nhà bình duyệt. Các phiên bản chỉnh sửa sẽ đều được lưu trữ cẩn thận trên hệ thống của F1000, và chỉ khi bài nghiên cứu vượt qua vòng phản biện thì chúng mới được chỉ mục hoá.
\end{abstract}

Từ năm 2016, nhiều quỹ tài trợ khoa học lớn như Wellcome hay Bill \& Melinda Gates Foundation đã ủng hộ nền tảng này với các hoạt động hợp tác cung cấp công nghệ và xây dựng nền tảng xuất bản riêng cho từng quỹ.

Ngày 10-1-2020 vừa qua, F1000 Research đã chính thức trở thành một phần của Taylor \& Francis. Cả hai đã tìm thấy sự đồng thuận về mục tiêu phát triển khoa học mở. Annie Callanan, giám đốc điều hành của Taylor \& Francis, cho biết F1000 Research sẽ giúp đẩy mạng các dịch vụ nghiên cứu mở và các nền tảng xuất bản đáp ứng yêu cầu Plan $\mathrm{S}$ của Taylor \& Francis; đồng thời, văn hoá sáng tạo và đổi mới của F1000 Research cũng sẽ giúp Taylor \& Francis tiếp tục cải thiện dịch vụ và mang tới các lựa chọn tốt nhất cho nhà khoa học.

Trong khi đó, nhà sáng lập F1000Research-Vitek Tracz-nhận định F1000 Research đã mang tới một cơ chế xuất bản học thuật hiệu quả và minh bạch; tuy nhiên, bây giờ là lúc nền tảng sáng tạo này cần sự hỗ trợ của một đối tác giàu kinh nghiệm hơn. Trong tương lai, theo giám đốc quản lý Rebecca Lawrence của F1000 Research, F1000 Research sẽ không chỉ gói gọn trong ngành khoa học sự sống và sẽ mở rộng ra cả nghệ thuật, khoa học xã hội và nhân văn [2].

Đối với lĩnh vực KHXH\&NV tại Việt Nam [3], F1000 Research vẫn là một nhà xuất bản mới mẻ với chỉ 18 tác giả từng công bố 4 nghiên cứu tại đây. Trong khi đó, 460 tác giả đã công bố 500 bài nghiên cứu trên 207 tạp chí của Taylor \& Francis. Sau cú chuyển nhượng bom tấn, các bài viết trên F1000 Research sẽ đạt tiêu chuẩn công bố trên các tạp chí quốc tế có uy tín của Quỹ NAFOSTED. Điều này giúp các nhà nghiên cứu Việt Nam có thêm một nền tảng xuất bản mở và đưa các kết quả mới nhất tới công chúng dễ dàng, tạo ra hiệu quả đầu tư khoa học [4]. 
Note: Published in EASE Vietnam SciComm System (12-01-2020): https://sc.sshpa.com/post/5605

\section{References}

[1] Taylor \& Francis. (2020). F1000 Research joins Taylor \& Francis Group. Taylor \& Francis. Retrieved from https://newsroom.taylorandfrancisgroup.com/f1000-research-joins-taylor-francis/ [January 18, 2020].

[2] Lawrence, R. (2020). F1000Research flies the nest. F1000Research blog. Retrieved from https://blog.f1000.com/2020/01/10/f1000research-flies-the-nest/ [January 18, 2020].

[3] Huyen, N. T. T., Dung, N. T., Nhan, N. T., Phuong, L. A., Linh, N. T., Le, T. K., \& Ho, M. T. (2020). KHXH\&NV: Hơn một thập kỷ tăng số lượng và chất lượng công bố quốc tế. Khoa học và Phát triển. $\quad$ Retrieved from http://khoahocphattrien.vn/chinh-sach/khxhnv-hon-mot-thap-ky-tang-so-luong-va-chat-luong-c ong-bo-quoc-te/20200113023839782p1c785.htm [January 18, 2020].

[4] Vuong, Q. H. (2018). The (ir)rational consideration of the cost of science in transition economies. Nature Human Behaviour, 2(1), 5, DOI: 10.1038/s41562-017-0281-4. 